\title{
Recycle and treatment of wastewater produced from pharmaceutical plant
}

\author{
Reda A.M. Nassef, Nashwa M.H. Rizk, Ibrahim E. Mousa*
}

Department of Environmental Biotechnology, Genetic Engineering and Biotechnology Research Institute, University of Sadat City, Menofiya, 22857 Egypt

Corresponding author; email: ibrahim23365@yahoo.com

\begin{abstract}
Direct discharge of treated effluent containing pharmaceuticals compounds (PCs) to natural water bodies raised concern regarding the effect of these persistent (escaped) compounds on the aquatic ecosystem. The presence of these PCs in the receiving environment causes disturbance of aquatic flora and fauna and risk to human health. Our study was concerned about removal efficiency of the removal comparing to Egyptian guidelines. Conventionally treated methods as physical, chemical, biological and reverse osmosis technologies were tested. The effectiveness of this system was verified by observing the effluent content such as microbial load during an operation period and total element content by ICP-MS. A result of adjusting $\mathrm{pH}$ and start mixing with sewage waste water showed the values for different item were decreased by $81 \%, 89 \%, 63 \%, 52 \%, 44 \%, 95 \%$, and $44 \%$ for BOD, COD, TSS, oil and grease, TP, TPH and H2S, respectively. The results showed the optimum removing for contamination between (16 hours to 36 hour) from start treatment, and the optimum pH ranged from 7 to 8 in case for biological treatment of pharmaceutical waste water and TDS decreased by $69 \%$ by RO system.
\end{abstract}

Key words: pharmaceuticals compounds, physical, chemical, biological treatment, RO system

\section{Introduction}

Pharmaceuticals and personal care products (PPCPs) are a group of substances that "refer, in general, to any product used by individuals for personal health or cosmetic reasons or used by agribusiness to enhance growth or health of livestock' (US-EPA). The term PPCPs contains thousands of different chemical compounds. Many of these compounds including pharmaceuticals are bioactive, metabolize partially, and

biodegrade slowly (Debska et al., 2004; Hernando et al., 2006; Kummerer, 2008). The presence of pharmaceuticals has raised concerns due to their deleterious effects in organisms and aquatic ecosystem (Fent et al., 2006; García et al., 2014; Overturf et al., 2015).

There are multiple possible emission pathways of pharmaceuticals into the 
environment (Bound and Voulvoulis, 2005). However, effluents of wastewater treatment plants (WWTPs) were generally recognized as the major emission pathway of pharmaceuticals into the environment (Kümmerer, 2001; Ramirez et al., 2009).Pharmaceutical industries consume large amounts of water in the pharmaceutical manufacturing processes and generate highly polluted toxic wastewaters (Gadipelly et al., 2014).

Direct discharge of treated effluent (containing pharmaceuticals) from WWTP to natural water bodies raised concern regarding the effect of these persistent (escaped) compounds on the aquatic ecosystem. The presence of these pharmaceutical contaminants in the receiving environment causes disturbance of aquatic flora and fauna and risk to human health. Many short-term toxicity studies reported that the drug molecules do not have an acute toxic effect on aquatic organisms because of their presence in low concentration, but their constant release and exposure to aquatic biota have long-term (chronic) effects. In laboratory studies, it was observed that estrogen induce vitellogenesis in male and high estrogenicity increases the mortality rate of fish (Jukosky et al., 2008).

Prolonged exposure to pharmaceuticals in low concentration leads to the change in species trait and behaviour of aquatic organisms. The well-known example of the Shift in species trait is the feminization of male fish due to the presence of estrogen in the aquatic environment (Gross-Sorokin et al., 2005).
High consumption of pharmaceuticals led to concomitant concern observing its presence in the environment because a large proportion of these therapeutic compounds cannot be assimilated and metabolized by the human body, thus excreted via feces and urine and enters into municipal wastewater treatment plant (WWTP). The main constituents of pharmaceutical waste are antibiotics, chemotherapy products, hormones, analgesic, antipyretic and antidepressants. Many studies revealed that the presence of various pharmaceutical in the aquatic environment (Ferrando - Climent et al., 2014).

Pharmaceuticals are biologically active compounds that are known to have a particular mode of action in human and animals. Before the beginning of 19th century, natural compounds were the principal source of therapeutic. Plants crude extracts, shrubs are the herbal medicines, which are used for pain relief, healing wounds, and for treating various types of illness.

Our study, concern about removal efficiency of all insoluble component, and decreasing pharmaceutical compound and detect the percentage of removal and Comparison to Egyptian guide line will be done. Conventionally treated methods could be used for wastewater treatment through physical, chemical and biological technologies. The effectiveness of this system was verified by observing the effluent content such as microbial load during an operation period by, total element content (ICP-MS), Biological Oxygen Demand (BOD), Chemical Oxygen Demand (COD), 
Total suspended Solids (TSS), $\mathrm{pH}$ and Total Dissolved Solids (TDS).

\section{Materials and methods}

LIPTIS Egypt Factory has two draining systems separately, one separated draining network specified for industrial sewage and the other is separate domestic network for normal use sewage drainage system.

1- Settling tank using bottle has $40 \mathrm{~L}$ which using waste water from detected point, this water has two properties (pharmaceutical\& sanitary) starting treatment.

2- Aeration tank has specified as total volume 2 liter with $\left(\mathrm{h}=20^{*} \mathrm{x}=10^{*} \mathrm{y}=10\right)$ $\mathrm{cm}$,the water transfer to it depending on osmosis phenomenal from settling tank ,we add air by using air jet pump and water transfer from this tank to the second by over flow.

3- Anaerobic tank has specification with total volume 2 Liter with $\left(\mathrm{h}=15^{*} \mathrm{x}=10^{*} \mathrm{y}=\right.$ 13.3) $\mathrm{cm}$, the velocity of water 300 $\mathrm{ml} / \mathrm{min}$, and water transfer from tis tank to the third stage by over flow.

4- Sedimentation tank has specification with total volume 2 Liter with $(\mathrm{h}=10 * \mathrm{x}=10 * \mathrm{y}=$ 20) $\mathrm{cm}$, this tank settling the suspended solid on bottom and the clear water over flow to new bottle to complete the treatment by chemical and physical method.

5- Reversal Osmosis (RO ) stage and the main stage for removal excess from salt and dissolved material after biological and chemical treatment and product water can used a gain in cleaning or garden after pass on UV System to control on all contamination. due to have same characteristic approved from environmental, after using method for treatment above we can coast reduction of water using in agricultures places in side plant.

\section{Results and Discussion}

Raw waste water characteristic:-

The raw wastewaters were characterized from multiple collected samples, although we take sample from the Sam point before starting $\mathrm{pH}$ equalization system and before that mixing with sewage waste water (Table 1), that includes $\mathrm{pH}, \mathrm{BOD}, \mathrm{COD}$, TSS, oil and grease, TP, TPH and $\mathrm{H}_{2} \mathrm{~S}$.

Also, the limits of wastewater quality according to EEAA (act \# 44/2000) is listed that shows the most parameters fit in low concentrations and has ability to discharge to the sanitary system. According to the Table (1), the biological viability of the raw waste water have average value $55 \pm 14 \%$ meaning this water has a good opportunity for biological treatment. The most parameters show moderate features that create a good condition for microorganism's growth as shown in Fig.(1). 


\section{BOD/COD ratio}

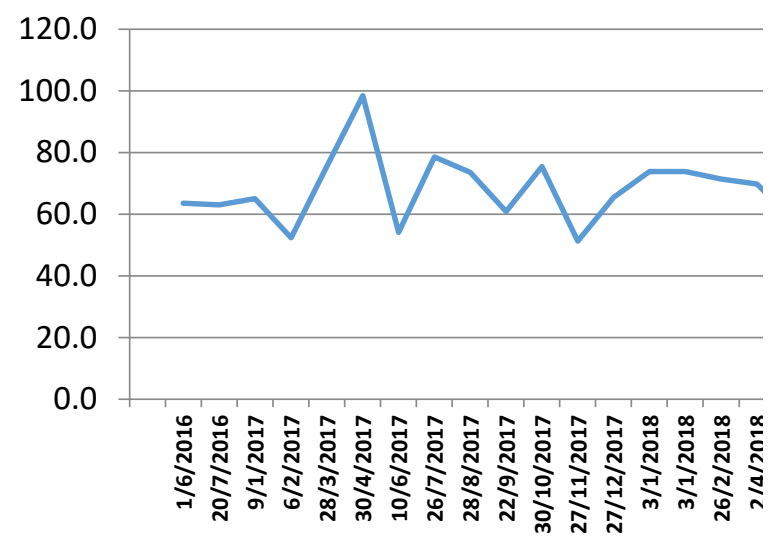

Figure (1): Bioavailability of wastewater

by BOD/COD ratio.

Table (1): Raw wastewater characteristic:-

\begin{tabular}{|c|c|c|c|c|c|c|c|c|c|}
\hline Date & $\mathrm{pH}$ & $\begin{array}{c}\mathrm{BOD} \\
\mathrm{mg} / \mathrm{l}\end{array}$ & $\begin{array}{c}\mathrm{COD} \\
\mathrm{mg} / \mathrm{l}\end{array}$ & $\begin{array}{c}\mathrm{TSS} \\
\mathrm{mg} / \mathrm{l}\end{array}$ & $\begin{array}{c}\mathrm{G} \& \mathrm{O} \\
\mathrm{mg} / \mathrm{l}\end{array}$ & $\begin{array}{c}\mathrm{TN} \\
\mathrm{mg} / \mathrm{l}\end{array}$ & $\begin{array}{c}\mathrm{TP} \\
\mathrm{mg} / \mathrm{l}\end{array}$ & $\begin{array}{c}\mathrm{TPH} \\
\mathrm{mg} / \mathrm{l}\end{array}$ & $\begin{array}{c}\mathrm{H}_{2} \mathrm{~S} \\
\mathrm{mg} / \mathrm{l}\end{array}$ \\
\hline $1 / 6 / 2016$ & 7.82 & 356 & 560 & 180 & 9 & 23 & 11 & 0.01 & 9 \\
\hline $20 / 7 / 2016$ & 7.25 & 290 & 460 & 200 & 17 & 22 & 19 & $0.01>$ & 7.8 \\
\hline $9 / 1 / 2017$ & 8.7 & 410 & 630 & 245 & 20 & 15 & 12 & $0.01>$ & 9 \\
\hline $6 / 2 / 2017$ & 8.27 & 220 & 420 & 180 & 8 & 48 & 12 & $0.01>$ & 8 \\
\hline $28 / 3 / 2017$ & 8.32 & 136 & 180 & 120 & 6 & 28 & 8 & $0.01>$ & 1 \\
\hline $30 / 4 / 2017$ & 7.83 & 180 & 183 & 98 & 15 & 20 & 18 & $0.01>$ & 2 \\
\hline $10 / 6 / 2017$ & 7.67 & 130 & 240 & 120 & 10 & 25 & 10 & 0.01 & 8 \\
\hline $26 / 7 / 2017$ & 7.17 & 110 & 140 & 98 & 10 & 14 & 6 & 0.01 & 9 \\
\hline $28 / 8 / 2017$ & 7.54 & 125 & 170 & 110 & 8 & 22 & 12 & 0.01 & 8 \\
\hline $22 / 9 / 2017$ & 7.82 & 112 & 184 & 130 & 12 & 25 & 6 & 0.01 & 9 \\
\hline $30 / 10 / 2017$ & 7.65 & 95 & 126 & 84 & 8.9 & 26.5 & 11.2 & 0.01 & 9 \\
\hline $27 / 11 / 2017$ & 7.82 & 123 & 240 & 110 & 3.5 & 20.6 & 8.6 & 0.01 & 6 \\
\hline $27 / 12 / 2017$ & 7.23 & 95 & 145 & 78 & 3.9 & 42 & 4.5 & 0.01 & 8 \\
\hline $3 / 1 / 2018$ & 7.63 & 110 & 149 & 75 & 2.5 & 30 & 5 & $0.01>$ & 6 \\
\hline $3 / 1 / 2018$ & 7.63 & 110 & 149 & 75 & 2.5 & 30 & 5 & $0.01>$ & 6 \\
\hline $26 / 2 / 2018$ & 7.65 & 150 & 210 & 115 & 10 & 50 & 10 & $0.01>$ & 5 \\
\hline $2 / 4 / 2018$ & 7.96 & 60 & 86 & 60 & 2.5 & 10 & 5 & $0.01>$ & 8 \\
\hline $28 / 5 / 2018$ & 7.45 & 84 & 144 & 32 & 2 & 56 & 10 & $0.01>$ & 6 \\
\hline $\begin{array}{c}\text { Average } \\
\text { value }\end{array}$ & 7.7 & 160.9 & 245.3 & 117.2 & 8.4 & 28.2 & 9.6 & 0.0 & 6.9 \\
\hline & & & & & & & & & 6 \\
\hline
\end{tabular}




\section{Metal contents of wastewater}

The raw wastewaters were characterized from multiple collected samples as shown in Table (2) measuring concentrations of metal content in waste water, this test including 23 elements, and take average value for each element.

\section{Anaerobic treatment}

The effected off sludge after mixing with industrial sewage, we using air pump to generation of air to measuring effect of degradation during aerobic treatment conations as shown in Figure (2).

Table (2): Metal content raw wastewaters collecting before dosing system, with average value and stander deviation.

\begin{tabular}{|c|c|c|c|c|}
\hline & $\mathrm{R} 1$ & $\mathrm{R} 2$ & Average & SD \\
\hline $7 \mathrm{Li}$ & 19 & 33 & 26 & 9.9 \\
\hline $\mathrm{B} 11$ & 215 & 81 & 148 & 94.8 \\
\hline $23 \mathrm{Na}$ & 8,753 & 55 & 4404 & 6150.4 \\
\hline $24 \mathrm{Mg}$ & 257 & 523 & 390 & 188.1 \\
\hline $27 \mathrm{Al}$ & 2,740 & 100 & 1420 & 1866.8 \\
\hline $39 \mathrm{~K}$ & 515 & 586 & 550.5 & 50.2 \\
\hline $44 \mathrm{Ca}$ & 124 & 172 & 148 & 33.9 \\
\hline $48 \mathrm{Ti}$ & 18 & 387 & 202.5 & 260.9 \\
\hline $52 \mathrm{Cr}$ & 62 & 2 & 32 & 42.4 \\
\hline $55 \mathrm{Mn}$ & 56 & 21 & 38.5 & 24.7 \\
\hline $57 \mathrm{Fe}$ & 2 & 140 & 71 & 97.6 \\
\hline $59 \mathrm{Co}$ & 11 & 1 & 6 & 7.1 \\
\hline $60 \mathrm{Ni}$ & 99 & 1 & 50 & 69.3 \\
\hline $63 \mathrm{Cu}$ & 247 & 212 & 229.5 & 24.7 \\
\hline $66 \mathrm{Zn}$ & 25 & 12 & 18.5 & 9.2 \\
\hline $71 \mathrm{Ga}$ & 30 & 1 & 15.5 & 20.5 \\
\hline $88 \mathrm{Sr}$ & 1 & 19 & 10 & 12.7 \\
\hline $107 \mathrm{Ag}$ & 5 & 2 & 3.5 & 2.1 \\
\hline $111 \mathrm{Cd}$ & 12 & 1 & 6.5 & 7.8 \\
\hline
\end{tabular}




\begin{tabular}{|c|c|c|c|c|}
$115 \mathrm{In}$ & 419 & 1 & 210 & 295.6 \\
\hline $137 \mathrm{Ba}$ & 1 & 50 & 25.5 & 34.6 \\
\hline $208 \mathrm{~Pb}$ & 72 & 4 & 38 & 48.1 \\
\hline $209 \mathrm{Bi}$ & 5 & 1 & 3 & 2.8 \\
\hline
\end{tabular}

(A)

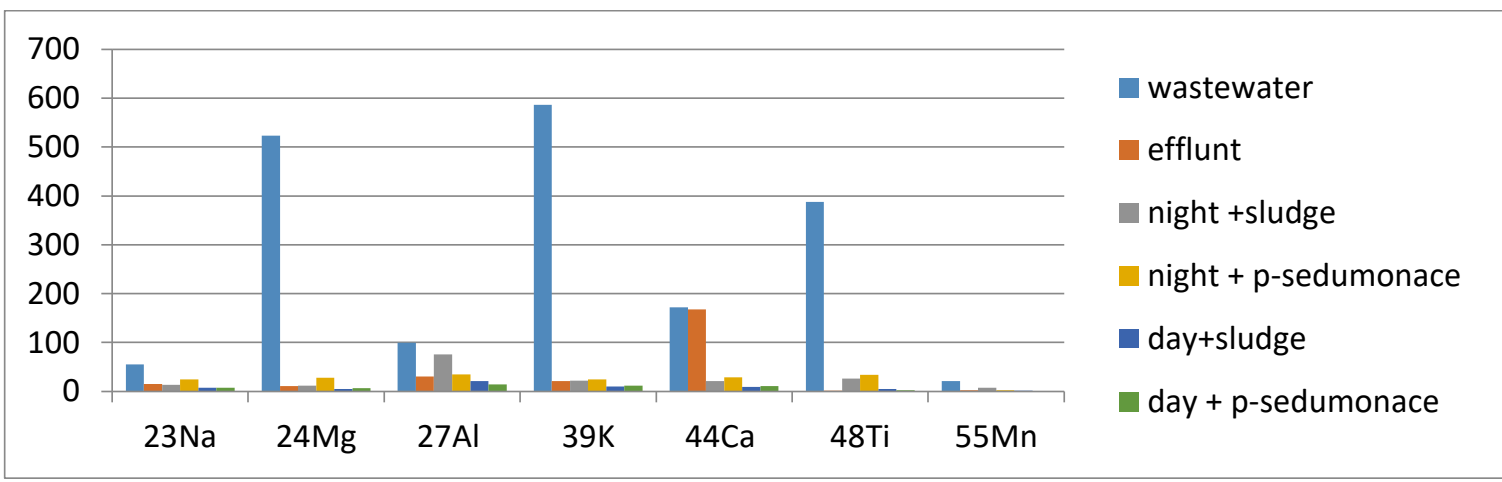

(B)

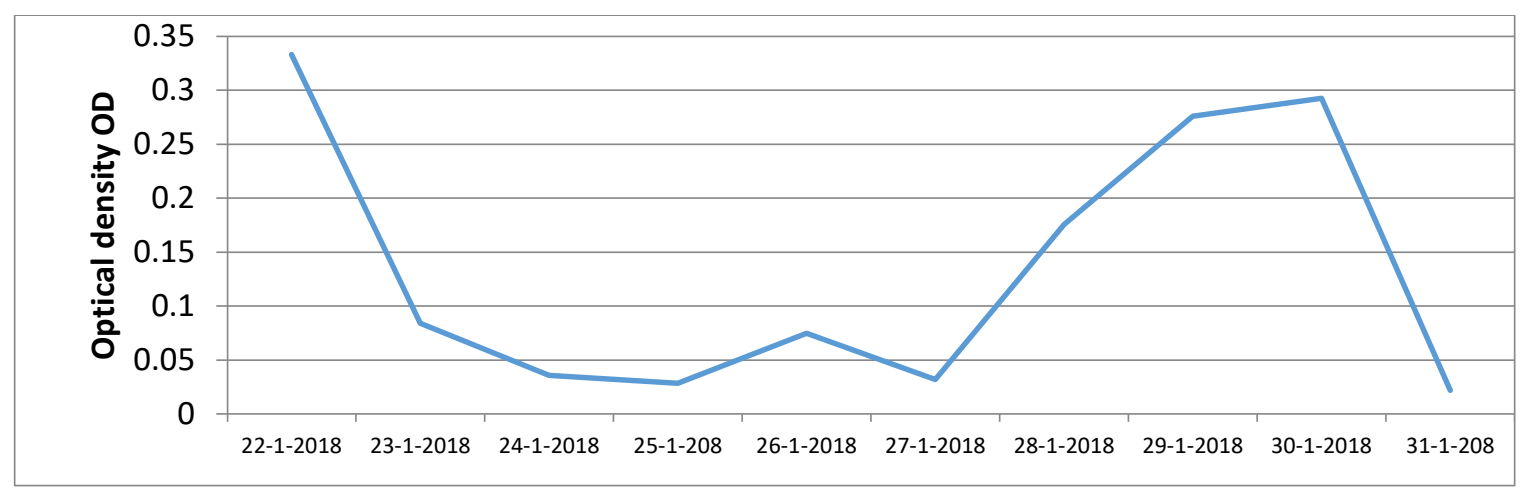

Figure (2):- The value of metals as results of microbial addition (A) and TSS as optical density (OD) by using T80UK during 10 days (B). 


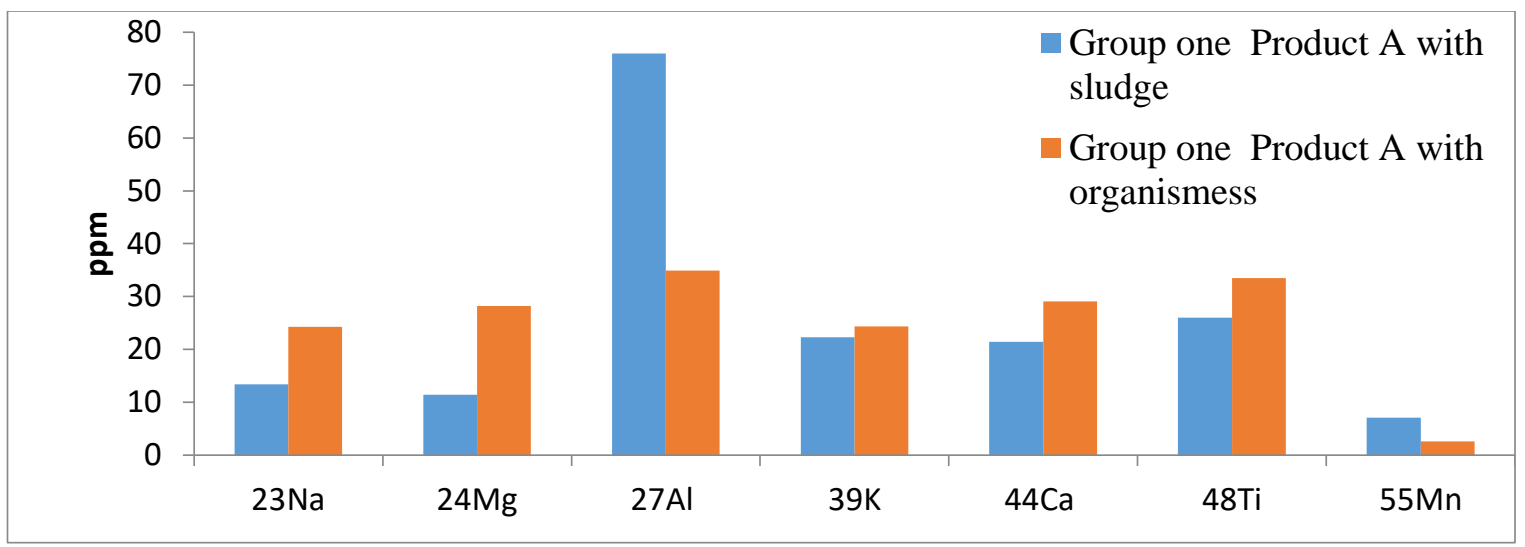

Figuer (3): The effect of change of organisms on pharmaceutical waste water first group.

Figure (3) shows that during last experiment the results appearing in case of sludge from sewage waste water, the experiments make under aerobic conditions obtunding good result, this result appearing in figure (3) for degradation of different element except Al. According Figure (4) the value for TDS is linear decreased and fixed in at $200 \mathrm{ppm}$, so this water can be used for cleaning in different places in side plants, and decreased the amount of water used from city water and cost reduction for water in side plant .the efficiency for RO membrane and the recovery for RO system from $68 \%-79 \%$ during this experimental.

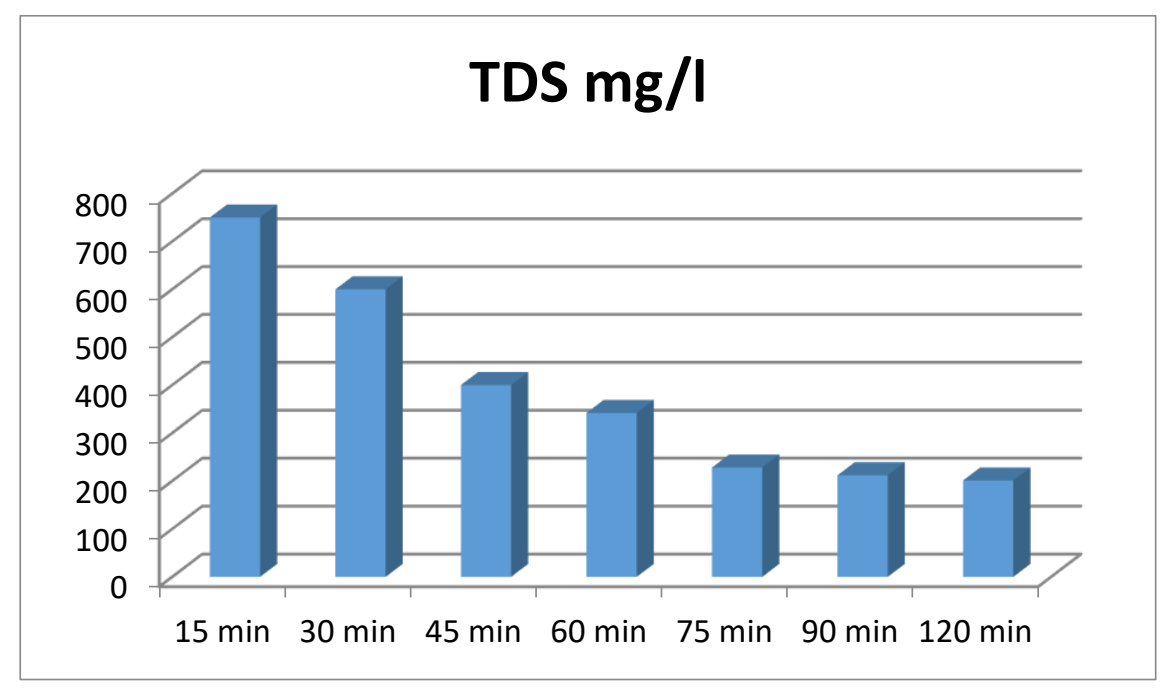

Figure (4): Characteristic for TDS from RO water produced in last stage.

According to Figure (5) and (6), the different between the influent pharmaceuticals waste water and effluent after last stage (RO). And effective of treatment on pharmaceutical waste water characteristic the unit by ppm. 


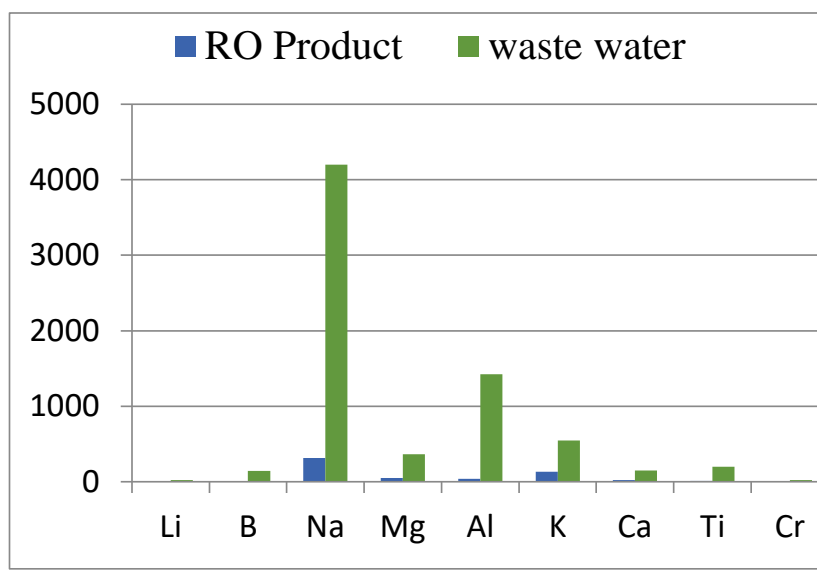

Figure (5): Effect of treatment on pharmaceutical waste water.

According comparison between result from treatment by biological treatment by different mechanisms appearing in Table (6), (7) and Table (10)which has value for metal content after using physical treatment by RO system , observation decreasing in all value after using RO system, and which has the recovery for RO system by more than 69 $\%$. And also cheek the result from Table (9) the value for all data in limit for city water, and using dosing for chlorine to control on microorganisms before using this water in side plant, so the water produced from RO system was saving in tanks and add chlorine to this tanks by value not more than $0.5 \mathrm{mg} / \mathrm{l}$ so can using this water in different places in factory for pharmaceuticals.

\section{References}

1. Bound, J.P., Voulvoulis, N., 2005. Household disposal of pharmaceuticals as apathway for aquatic contamination in the United Kingdom. Environ. Health Perspect. 113, 1705-1711.

2. Debska, J., Kot-Wasik, A., Namiesnik, J., 2004. Fate and analysis of pharmaceutical residues in the aquatic environment. Crit. Rev. Anal. Chem. 34 (1), 51-67.

3. Fent, K., Weston, A.A., Caminada, D., 2006. Ecotoxicology of human

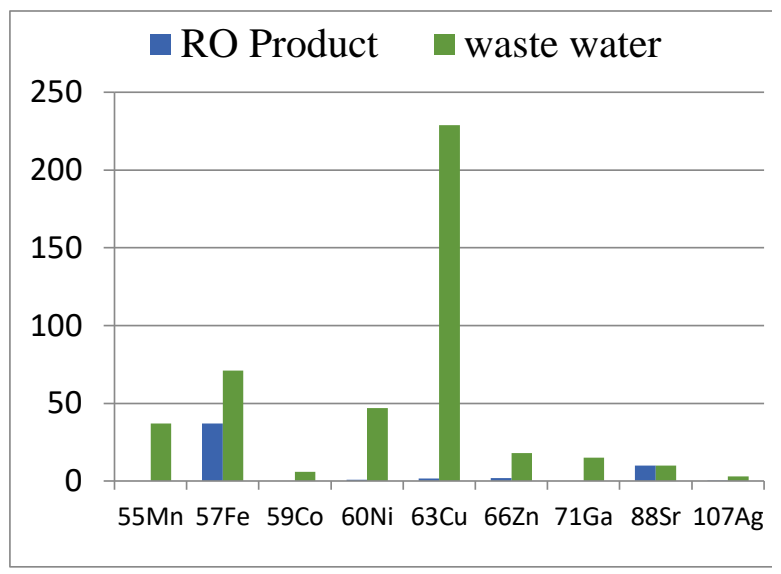

Figure (6): Effect of treatment on pharmaceutical waste water.

pharmaceuticals. Aquat. Toxicol. 78 (2), (207-207).

4. Ferrando-Climent, L., Rodriguez-Mozaz, S., Barceló, D., 2014. Incidence of anticancer drugs in an aquatic urban system: from hospital effluents through urban wastewater to natural environment. Environ. Pollut. 193, 216-223.

5. Gadipelly, C., P_erez-Gonz_alez, A., Yadav, G.D., Ortiz, I., Ib_a a nez, R., Rathod, V.K., Marathe, K.V., 2014. Pharmaceutical industry wastewater: review of the technologies for water treatment and reuse. Ind. Eng. Chem. Res. 53 (29),1157111592.

6. García, S.A.O.D., Pinto, G.P., GarcíaEncina, P.A., Irusta-Mata, R., 2014. Ecotoxicity and environmental risk assessment of pharmaceuticals and personal care products in aquatic environments and wastewater treatment plants. Ecotoxicology 23,1517e1533.

7. García, S.A.O.D., Pinto, G.P., GarcíaEncina, P.A., Irusta-Mata, R., 2014. Ecotoxicity and environmental risk assessment of pharmaceuticals and personal care products in aquatic environments and wastewater treatment plants. Ecotoxicology 23, 1517-1533.

8. Gross-Sorokin, M.Y., Roast, S.D., Brighty, G.C., 2005. Assessment of feminization of male fish in English rivers by the Environment Agency of England and Wales. Environ. Health Perspect. 114 (S-1), 147151. 
9. Hernando, M.D., Mezcua, M., Fernandez-

Alba, A.R., Barcelo, D., 2006.

Environmental risk assessment of pharmaceutical residues in wastewater effluents, surface waters and sediments. Talanta 69, 334-342.

10. Jukosky, J.A., Watzin, M.C., Leiter, J.C., 2008. The effects of environmentally relevant mixtures of estrogens on Japanese medaka (Oryzias latipes) reproduction. Aquat. Toxicol. 86 (2), 323-331.

11. Kümmerer, K., 2001. Pharmaceuticals in the Environment: Sources, Fate, Effects and Risks. Springer.

12. Kummerer, K., 2008. Pharmaceuticals in the environment - A brief summary. In: Kummerer, K. (Ed.), Pharmaceuticals in the Environment: Sources, Fate, Effects and Risks. Springer, Berlin, pp. 3-22.

13. Overturf, M.D., Anderson, J.C., Pandelides, Z., Beyger, L., Holdway, D.A., 2015. Pharmaceuticals and personal care products: a critical review of the impacts on fish reproduction. Crit. Rev. Toxicol. 45, 469-491.

14. Overturf, M.D., Anderson, J.C., Pandelides, Z., Beyger, L., Holdway, D.A., 2015. Pharmaceuticals and personal care products: a critical review of the impacts on fish reproduction. Crit. Rev. Toxicol. 45, 469-491.

15. Ramirez, A.J., Brain, R.A., Usenko, S., Mottaleb, M.A., O'Donnell, J.G., Stahl, L.L., Wathen, J.B., Snyder, B.D., Pitt, J.L., Perez-Hurtado, P., Dobbins, L.L., Brooks, B.W., Chambliss, C.K., 2009.

Occurrence of pharmaceuticals and personal care products in fish: results of a national pilot study in the United States. Environ. Toxicol. Chem. 28, 2587-2597. 